\title{
A biomechanical analysis of four anterior cervical techniques to treating multilevel cervical spondylotic myelopathy: a finite element study
}

Zhonghai $\mathrm{Li}^{1,2^{*}+}$, Hui Liu ${ }^{3+}$, Ming Yang ${ }^{1,2}$ and Wentao Zhang ${ }^{1,2}$

\begin{abstract}
Background: The decision to treat multilevel cervical spondylotic myelopathy (MCSM) remains controversial. The purpose of this study is to compare the biomechanical characteristics of the intervertebral discs at the adjacent segments and internal fixation, and to provide scientific experimental evidence for surgical treatment of MCSM.

Methods: An intact C2-C7 cervical spine model was developed and validated. Four additional models were developed from the fusion model, including multilevel anterior cervical discectomy and fusion (mACDF), anterior cervical corpectomy and fusion (ACCF), hybrid decompression and fusion (HDF), and mACDF with cage alone (mACDF-CA). Biomechanical characteristics on the plate and the disc of adjacent levels (C2/3, C6/7) were comparatively analyzed.
\end{abstract}

Results: Of the four models, stress on the upper (C2/3) adjacent intervertebral disc was the lowest in the mACDFCA group and highest in the ACCF group. Stress on the intervertebral discs at adjacent segments was higher for the upper C2/3 than the lower C6/7 intervertebral disc. In all models, the mACDF-CA group had the lowest stress on the intervertebral disc, while the ACCF group had the highest stress. In the three surgical models with titanium plate fixation (mACDF, ACCF, and HDF), the ACCF group had the highest stress at the titanium plate-screw interface, while the mACDF group had the lowest stress.

Conclusion: Among the four anterior cervical reconstructive techniques for MCSM, mACDF-CA makes little effect on the adjacent disc stress, which might reduce the incidence of adjacent segment degeneration (ASD) after fusion. However, the accompanying risk of the increased incidence of cage subsidence should never be neglected.

Keywords: Multilevel cervical spondylotic myelopathy, Anterior cervical corpectomy and fusion, Anterior cervical discectomy and fusion, Biomechanics, Finite element analysis

\footnotetext{
* Correspondence: lizhonghaispine@126.com

'Zhonghai and Hui Liu contributed equally to the manuscript and should be considered co-first authors.

'Department of Orthopaedics, First Affiliated Hospital of Dalian Medical University, Dalian, People's Republic of China

${ }^{2}$ Key Laboratory of Molecular Mechanism for Repair and Remodeling of Orthopaedic Diseases, Liaoning Province, People's Republic of China

Full list of author information is available at the end of the article
}

C C The Author(s). 2021 Open Access This article is licensed under a Creative Commons Attribution 4.0 International License, which permits use, sharing, adaptation, distribution and reproduction in any medium or format, as long as you give appropriate credit to the original author(s) and the source, provide a link to the Creative Commons licence, and indicate if changes were made. The images or other third party material in this article are included in the article's Creative Commons licence, unless indicated otherwise in a credit line to the material. If material is not included in the article's Creative Commons licence and your intended use is not permitted by statutory regulation or exceeds the permitted use, you will need to obtain permission directly from the copyright holder. To view a copy of this licence, visit http://creativecommons.org/licenses/by/4.0/. The Creative Commons Public Domain Dedication waiver (http://creativecommons.org/publicdomain/zero/1.0/) applies to the data made available in this article, unless otherwise stated in a credit line to the data. 


\section{Background}

Multilevel cervical spondylotic myelopathy (MCSM) refers to cervical spondylosis diagnosed by imaging with three or more levels of contiguous or noncontiguous cervical intervertebral disc degeneration and secondary changes, which causes compression on the dural sac and spinal cord, and which results in corresponding clinical manifestations. Owing to severe spinal cord compression in most cases, MCSM often requires surgery to relieve the compression. Consensus has currently been reached on the surgical management of CSM involving one or two mobile segments; however, controversy remains regarding the selection of surgical procedures for treatment of MCSM [1-3].

An anterior, posterior, or combined anterior-posterior approach can be employed according to the clinical situation and the experience of surgeons, and each approach has its unique advantages and disadvantages [3-12]. The anterior techniques such as multilevel anterior cervical discectomy and fusion (mACDF), anterior cervical corpectomy and fusion (ACCF), and hybrid decompression and fusion (HDF) have been proved to be reliable and effective in spinal cord decompression, and sagittal alignment restoration and maintenance thus achieved a good clinical outcome. To increase the stability of cervical vertebrae and the fusion rate of bone graft after surgery, anterior cervical titanium plate fixation is widely used. Nevertheless, the anterior titanium plate protrudes from the anterior margin of the cervical vertebral body, causing relatively strong friction with soft tissue in the anterior cervical region. As a result, complications such as foreign body sensation in the anterior cervical region, dysphagia, and esophageal injury have been found after long-term follow-up [13-15]. Meanwhile, some researchers argue that the use of anterior cervical titanium plate increases the incidence of adjacent segment degeneration (ASD) [16-18].

To prevent complications associated with anterior cervical titanium plates and maintain the benefits of interbody cages with anterior plating system, a new zeroprofile, stand-alone device (Fidji cervical cage, Abbott Spine, Bordeaux, France) has been designed and used clinically [19]. In recent years, we performed mACDF using Fidji cervical cages alone (mACDF-CA) for the treatment of MCSM. In these studies, we found that mACDF-CA was associated with shorter operation time, less blood loss and cost of index surgery, and lower dysphagia incidence, and satisfactory results were achieved in preliminary clinical applications $[8,9,20]$. Despite these findings, biomechanical studies assessing anterior techniques for the treatment of MCSM appear only rarely in the literature, and no one compares mACDFCA to other anterior techniques in multilevel constructs. A biomechanical study using finite element (FE) analysis can help to elucidate the complex biomechanical properties of the cervical spine, including stresses, strains, and loads under different conditions [21-23]. This study was a biomechanical comparative analysis of four anterior cervical techniques based on FE model. The biomechanical characteristics of the intervertebral discs at the adjacent segments and internal fixation were analyzed to provide scientific experimental evidence for surgical treatment of MCSM.

\section{Methods \\ Development of FE model (C2-C7)}

A 3-dimensional FE model of a normal C2-C7 segment was created in this study. Geometric details of the human cervical spine (C2-C7) were obtained from a highresolution computed tomographic scan of a healthy Chinese male volunteer (age, 30 yrs.; height, $182 \mathrm{~cm}$; weight, $76 \mathrm{~kg}$ ) in our simulation. This study was approved by the medical ethics committee of First Affiliated Hospital of Dalian Medical University (PJ-KS-KY2020-55). All procedures were followed in accordance with relevant guidelines. The subject's skull and cervical spine were scanned using a CT scanner (Brilliance 64, Philips Electronics, Netherlands). The final CT images had a resolution of $0.54 \mathrm{~mm} \times 0.54 \mathrm{~mm}$ and the slice interval of $0.625 \mathrm{~mm}$.

Within the software Mimics 17.0 (Materialise Inc., Leuven, Belgium), these images were segmented and translated to various 3D solid volumes of all vertebrae. Then, the solid volumes were created to fill the spaces between the vertebrae to create intervertebral discs. The final constructs were exported as STL format files. The solid volume was then, respectively, imported into the software Geomagic Studio 12.0 (Geomagic Inc., USA), in which it was converted into a non-uniform rational Bspline surface geometry structure. The model components included cortical bone, cancellous bone, bony posterior elements, annulus fibrosus, nucleus pulposus, posterior facets, end plates, anterior longitudinal ligament, posterior longitudinal ligament, ligamentum flavum, interspinous ligament, and capsular ligaments (Fig. 1). To reduce the resources required for creating a mesh of the complex spinal geometry, ABAQUS 6.13 (Abaqus Inc., USA) was used to generate a tetrahedral mesh on the vertebrae and a hexahedral mesh on the discs. The material properties were assumed to be homogeneous and isotropic according to the published literature [24-29]. The annular fibers embedded in the ground substance were assembled in a crisscross manner. The facet joint was created as a nonlinear threedimensional contact problem using surface-to-surface contact elements. Surface to surface contact algorithm is used in defining facet joint interaction and friction coefficient was assumed to be 0.1 . The initial material 


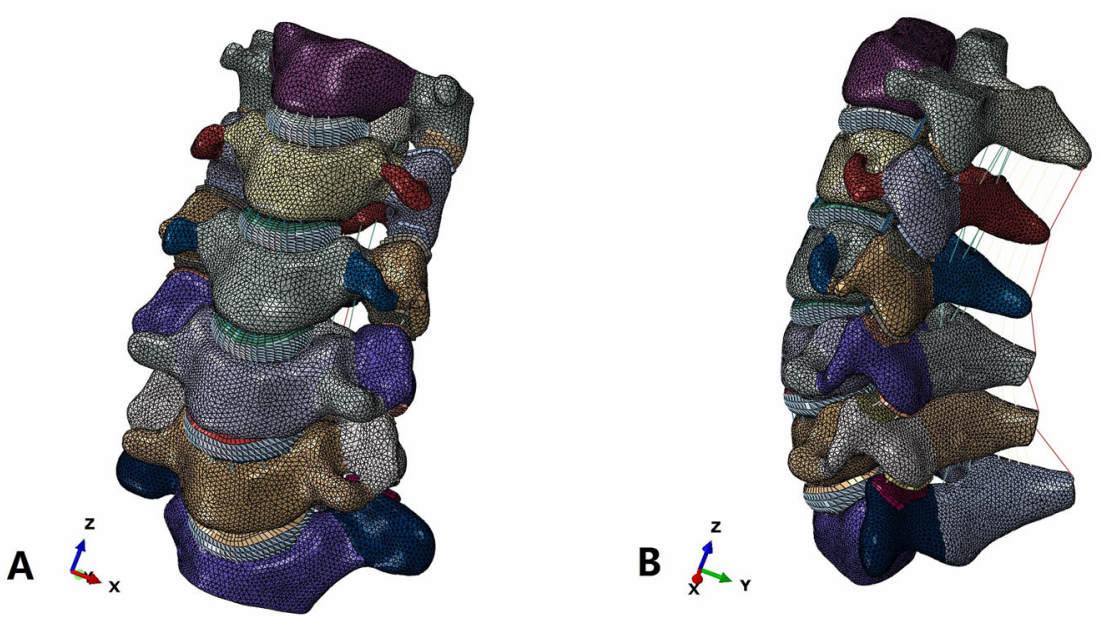

Fig. 1 A three-dimensional finite element model of intact cervical vertebra (C2-C7). a Front view, b Lateral view

properties were based on previous studies as shown in Table 1.

\section{Validation of model}

Three-dimensional surface contact elements were used for the contact and sliding effect between the articular facets. Statistical analysis was performed by applying 1.0 $\mathrm{Nm}$ of flexion, extension, axial rotation, and lateral bending moments with $73.6 \mathrm{~N}$ of axial compression superior to $\mathrm{C} 2$. The boundary condition was simulated by fixing the inferior surface of the $\mathrm{C} 7$ vertebra under constraint of different degrees of freedom. The validity of the FE model was verified by comparing the predicted data with the results reported in the literature [30-33].

\section{Surgery simulation}

First, a graphic of the titanium plates, screws, and PEEK interbody cages was drawn using the pre-processor modeling function of the FE software, ABAQUS/CAE. Small portions of the curved surfaces and threads were removed because these were considered not to affect the mechanical performance analysis, and rough models were constructed according to the structures of the titanium plates, screws, and cages.

Table 1 Material properties and element types of the spine soft tissues and hard tissues used in the finite element model

\begin{tabular}{|c|c|c|c|c|}
\hline Component & Element type & Young's modulus ( $\mathrm{MPa}$ ) & Cross-section $\left(\mathrm{mm}^{2}\right)$ & Poisson's ratio \\
\hline \multicolumn{5}{|l|}{ Bone } \\
\hline Cortical bone & Shell elements & 10,000 & - & 0.29 \\
\hline Cancellous bone & 3-D solid elements (4 node) & 100 & - & 0.29 \\
\hline \multicolumn{5}{|l|}{ Disc } \\
\hline Annulus (ground) & 3-D solid elements (8 node) & 4.2 & - & 0.45 \\
\hline Annulus (fiber) & 3-D solid elements (8 node) & 450 & - & 0.30 \\
\hline Nucleus & 3-D solid elements (8 node) & 1 & - & 0.49 \\
\hline End plate & 3-D solid elements & 500 & - & 0.40 \\
\hline \multicolumn{5}{|l|}{ Ligaments } \\
\hline Anterior longitudinal ligament & 3-D tension truss elements & 30 & 33 & 0.30 \\
\hline Posterior longitudinal ligament & 3-D tension truss elements & 20 & 33 & 0.30 \\
\hline Ligamentum flavum & 3-D tension truss elements & 5 & 50.1 & 0.30 \\
\hline Capsular ligaments & 3-D tension truss elements & 20 & 46.6 & 0.30 \\
\hline Interspinous ligament & 3-D tension truss elements & 1.5 & 13 & 0.39 \\
\hline \multicolumn{5}{|l|}{ Implants } \\
\hline PEEK cage & 3-D solid elements (4 node) & 3600 & - & 0.30 \\
\hline Titanium plate & 3-D solid elements (4 node) & 120,000 & - & 0.30 \\
\hline Titanium screw & 3-D solid elements (4 node) & 120,000 & - & 0.30 \\
\hline
\end{tabular}


mACDF model: The discectomies were simulated by removing the $\mathrm{C} 3 / 4, \mathrm{C} 4 / 5$, and $\mathrm{C} 5 / 6$ intervertebral discs and the corresponding anterior and posterior longitudinal ligaments. After decompression, a suitably sized PEEK interbody cage (height $5.8 \mathrm{~mm}$, width $14.6 \mathrm{~mm}$, and length $15.5 \mathrm{~mm}$ ) was place into each intervertebral disc space. After cages placement, a titanium plate (height $51.3 \mathrm{~mm}$, width $14.5 \mathrm{~mm}$, and thickness $2.3 \mathrm{~mm}$ ) was rigidly placed on the anterior C3-C6 vertebral bodies to provide additional stability to the fusion model. Along the ends of the anterior plate, two titanium screws were placed inside both C3 and C6 vertebral bodies within $1.00-\mathrm{mm}$ distance from the end plates. Unicortical screws of 16- and 18-mm length with a mean diameter of $3.0 \mathrm{~mm}$ were used. For all surgical models, the interfaces at the cage-endplate and screw-bone were defined as a tied contact condition to simulate a complete fusion status. ACCF model: The C3/4, C4/5, and $\mathrm{C} 5 / 6$ intervertebral discs were resected followed by corpectomy of the $\mathrm{C} 4$ and $\mathrm{C} 5$ vertebral bodies. Also, the anterior and posterior longitudinal ligament for the $\mathrm{C} 3 /$ $4, \mathrm{C} 4 / 5$, and C5/6 motion segments were excised. A bone graft (height $43.2 \mathrm{~mm}$, width $14.4 \mathrm{~mm}$, and length $15.2 \mathrm{~mm}$ ) with a cross-sectional area accounting for $50 \%$ of the vertebral endplate area was placed on the midline between the $\mathrm{C} 3$ and $\mathrm{C} 6$ vertebral bodies. The anterior margin of the bone graft was set $1.0 \mathrm{~mm} \mathrm{~mm}$ from the anterior margin of the vertebral bodies. Similar to the surgical procedure in $\mathrm{mACDF}$, ACCF model was fixed by the same anterior plate-screw system. For all surgical models, the interfaces at the bone graft-endplate and screw-bone were defined as a tied contact condition to simulate a complete fusion status.

HDF model: The $\mathrm{C} 3 / 4, \mathrm{C} 4 / 5$, and $\mathrm{C} 5 / 6$ intervertebral discs were resected, followed by corpectomy of the $\mathrm{C} 4$ vertebral body with both sides retained. Also, the anterior and posterior longitudinal ligament for the C3/4, C4/
5, and C5/6 motion segments were excised. A bone graft (height $26.7 \mathrm{~mm}$, width $14.4 \mathrm{~mm}$, and length $15.2 \mathrm{~mm}$ ) of the appropriate length was placed between the C3 and $\mathrm{C} 5$ vertebral bodies, $1.0 \mathrm{~mm}$ from the anterior margin of the vertebral bodies and centered between the left and right vertebral bodies. Similar to the surgical procedure in $\mathrm{mACDF}$, the same cage was placed in the $\mathrm{C} 5 /$ 6 intervertebral disc space. After cage placement, a titanium plate (height $34.6 \mathrm{~mm}$, width $14.5 \mathrm{~mm}$, and thickness $2.3 \mathrm{~mm}$ ) was rigidly placed on the anterior C3-C5 vertebral bodies. Unicortical titanium screws of 16- and $18-\mathrm{mm}$ length with a mean diameter of $3.0 \mathrm{~mm}$ were used.

mACDF-CA model: Similar to the surgical procedure in $\mathrm{mACDF}$, the $\mathrm{C} 3 / 4, \mathrm{C} 4 / 5$, and $\mathrm{C} 5 / 6$ intervertebral discs and the corresponding anterior and posterior longitudinal ligaments were resected and the same cage was placed in each intervertebral disc space. This technique did not require auxiliary anterior titanium plate fixation (Fig. 2).

\section{Results \\ Model validation}

The comparison between in vitro data and predicted value in the FE model are shown in Fig. 3. The ROMs of the intact model at $\mathrm{C} 2 / 3, \mathrm{C} 3 / 4, \mathrm{C} 4 / 5, \mathrm{C} 5 / 6$ and $\mathrm{C} 6 / 7$ were $4.43^{\circ}, 6.63^{\circ}, 7.56^{\circ}, 7.58^{\circ}$ and $5.21^{\circ}$, respectively, in flexion; $3.26^{\circ}, 4.76^{\circ}, 6.21^{\circ}, 5.41^{\circ}$ and $4.32^{\circ}$, respectively, in extension; $5.31^{\circ}, 5.59^{\circ}, 5.81^{\circ}, 4.12^{\circ}$ and $4.02^{\circ}$, respectively, in lateral bending; and $2.33^{\circ}, 3.32^{\circ}, 4.51^{\circ}, 3.74^{\circ}$ and $2.34^{\circ}$, respectively, in axial rotation. All the predicted responses were consistent with the results of previous biomechanical and FE analysis studies [30-33].

\section{Stress on the $\mathrm{C} 2 / 3$ intervertebral disc}

Of the four anterior cervical approaches, stress on the upper $(\mathrm{C} 2 / 3)$ adjacent intervertebral disc was the lowest

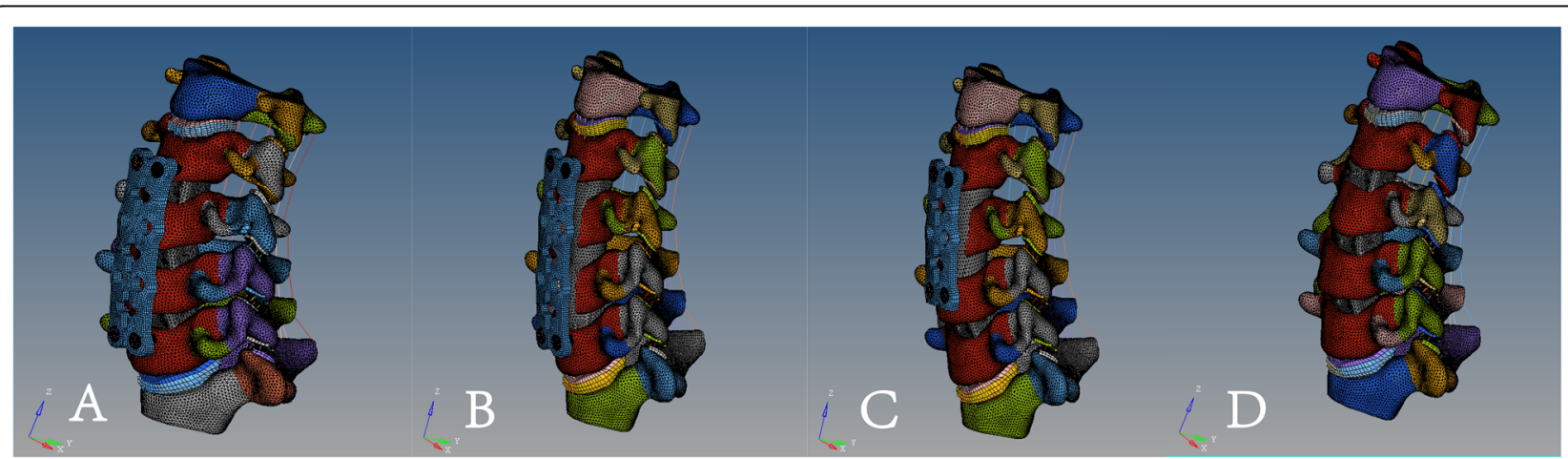

Fig. 2 A three-dimensional finite element model of four anterior cervical techniques. a multilevel anterior cervical discectomy and fusion $(\mathrm{mACDF}), \mathbf{b}$ anterior cervical corpectomy and fusion (ACCF), $\mathbf{c}$ hybrid decompression and fusion (HDF), $\mathbf{d}$ multilevel anterior cervical discectomy and fusion with cage alone (mACDF-CA) 


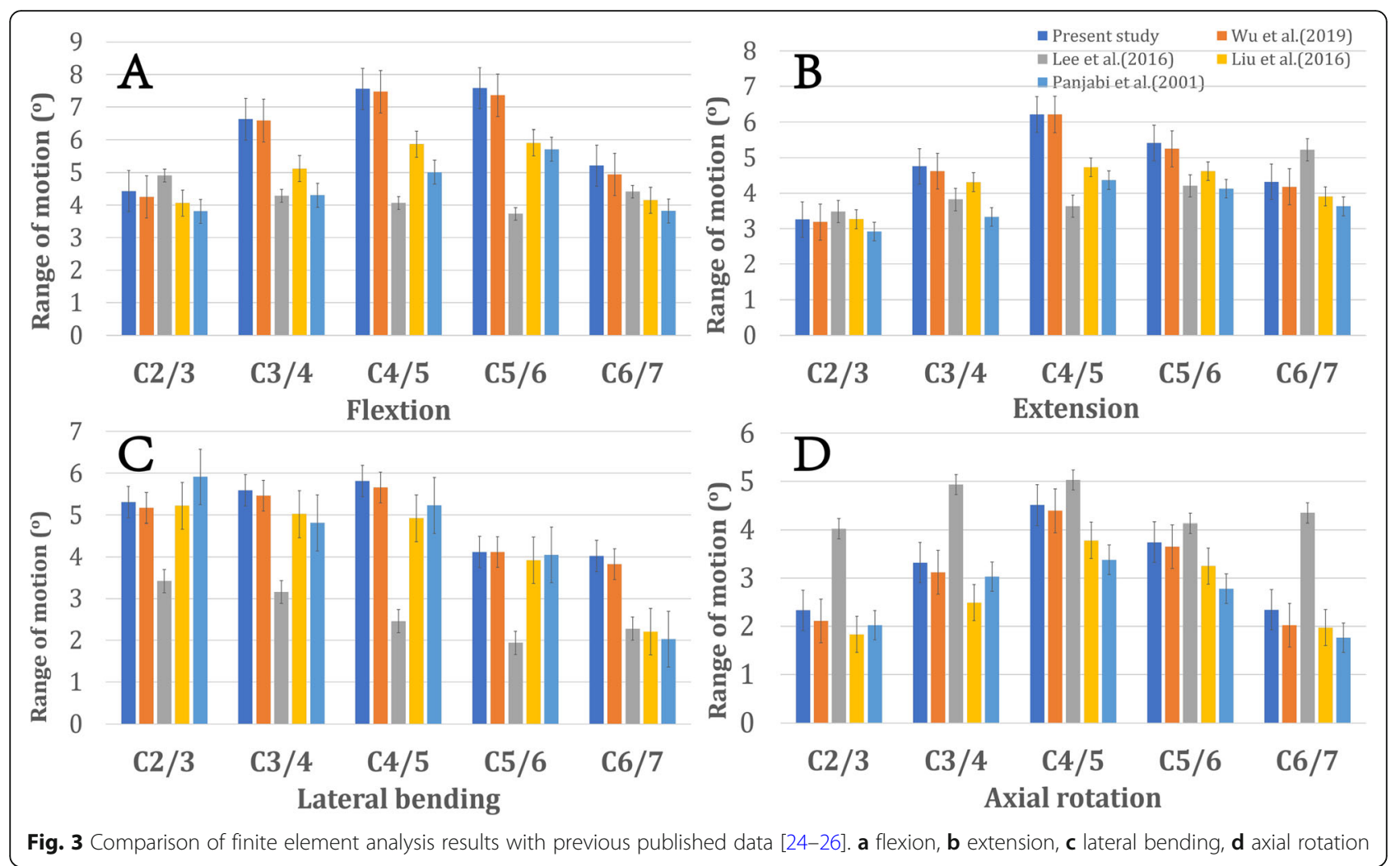

in the mACDF-CA group and highest in the ACCF group during flexion, extension, lateral bending, and rotation. Compared with the mACDF-CA group, the maximum von Mises stresses on the $\mathrm{C} 2 / 3$ intervertebral disc in the mACDF, ACCF, and HDF groups increased by 23 , 77 , and $72 \%$ during extension; by 42,49 , and $46 \%$ during lateral bending; and by 18, 104, and 105\% during rotation, respectively (Figs. 4 and 5).

\section{Stress on the $\mathbf{C 6 / 7}$ intervertebral disc}

With the four anterior cervical approaches, stress on the intervertebral discs at adjacent segments was higher for the upper $\mathrm{C} 2 / 3$ than the lower $\mathrm{C} 6 / 7$ intervertebral disc during flexion, extension, lateral bending, and rotation. In all models, the mACDF-CA group had the lowest stress on the intervertebral disc, while the ACCF group had the highest stress.

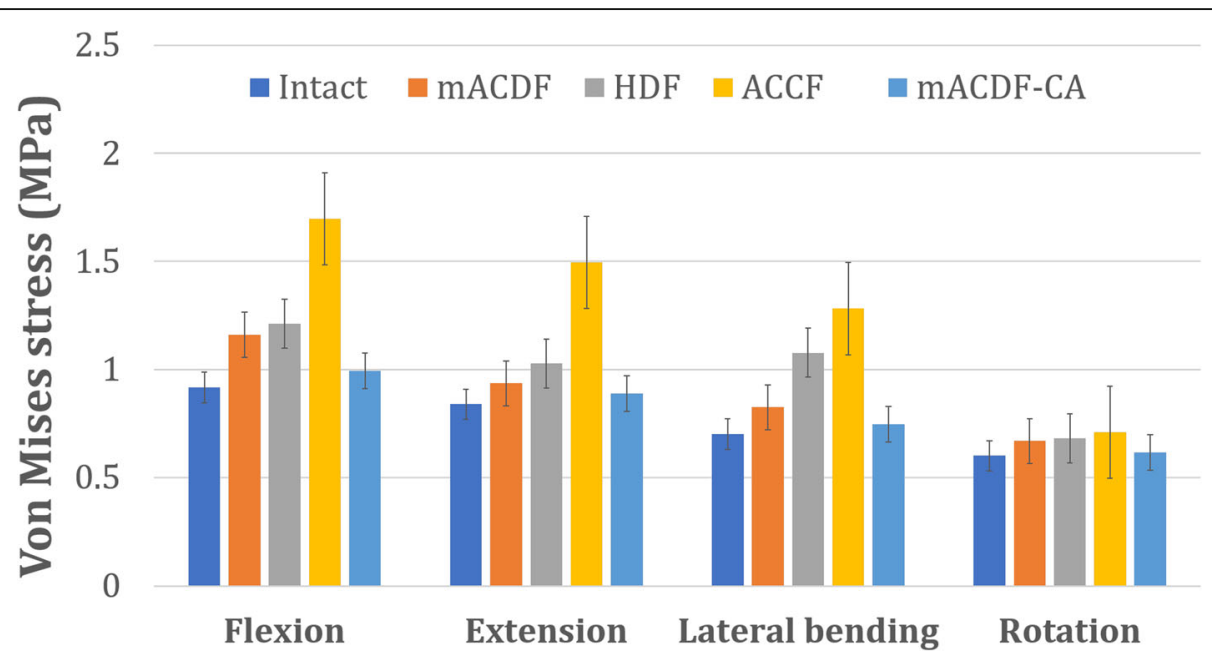

Fig. 4 Von Mises stress at C2/3 disc in different conditions in the four models of anterior anterior cervical techniques. mACDF, multilevel anterior cervical discectomy and fusion; ACCF, anterior cervical corpectomy and fusion; HDF, hybrid decompression and fusion; mACDF-CA, multilevel anterior cervical discectomy and fusion with cage alone 


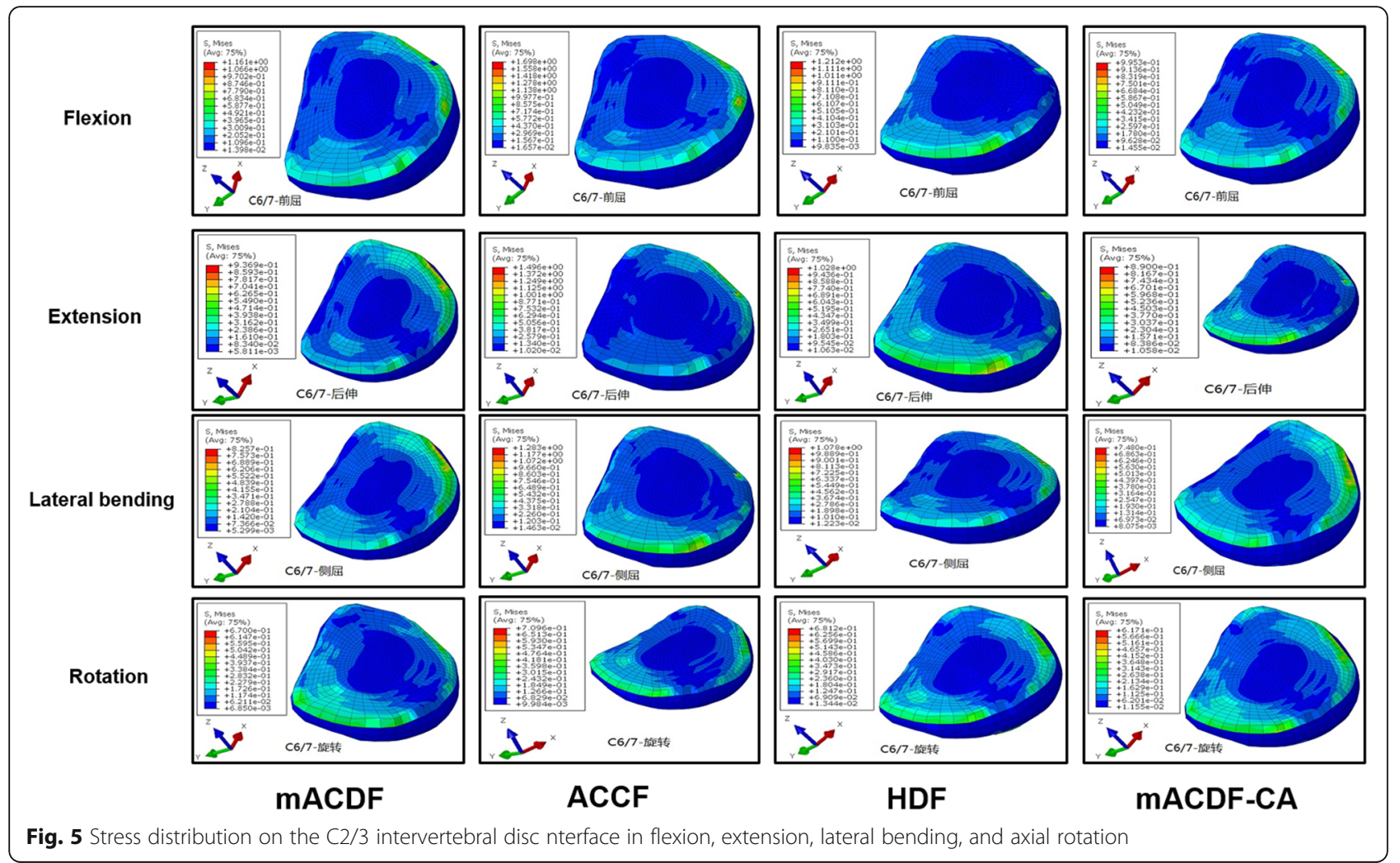

Compared with the mACDF-CA group, the maximum von Mises stresses on the lower (C6/7) adjacent intervertebral disc in the mACDF, $A C C F$, and HDF groups increased by 17,71 , and $22 \%$ during flexion; by 5,68 , and $16 \%$ during extension; by 10,72 , and $44 \%$ during lateral bending; and by 9,15 , and $10 \%$ during rotation, respectively (Figs. 6 and 7).

\section{Stress at the titanium plate-screw interface}

In the three surgical models with titanium plate fixation (mACDF, ACCF, and HDF), stress at the titanium platescrew interface was highest under flexion load and lowest under extension load. Of the three models, the ACCF group had the highest stress at the interface, while the mACDF group had the lowest stress (Figs. 8 and 9).

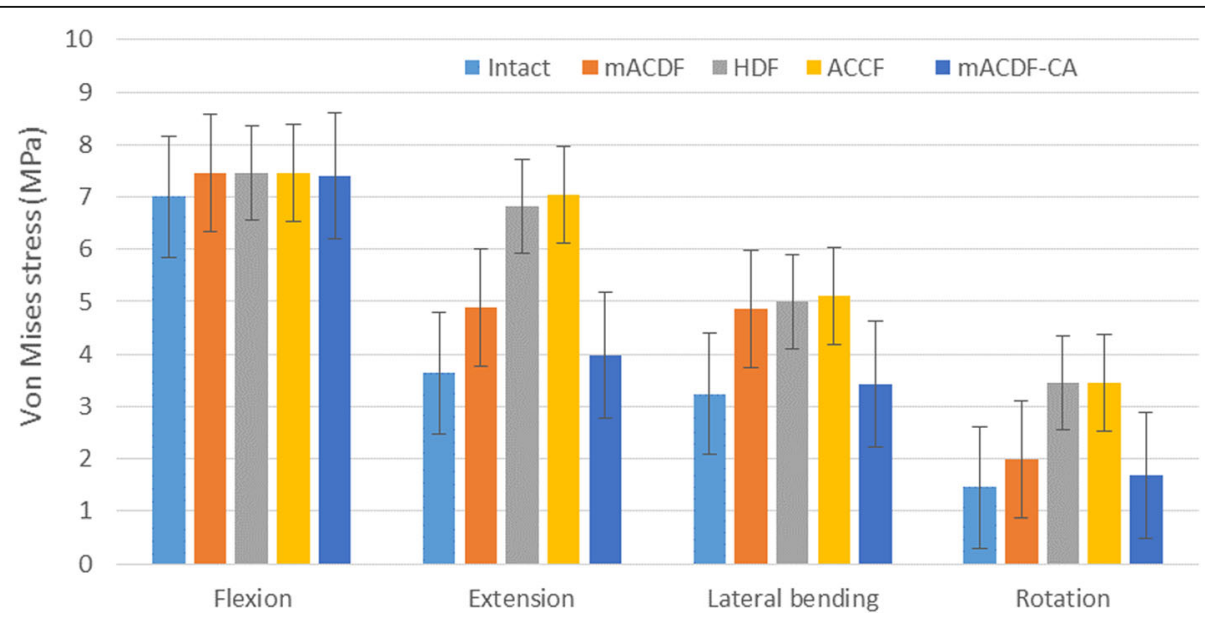

Fig. 6 Von Mises stress at C6/7 disc in different conditions in the four models of anterior anterior cervical techniques. mACDF, multilevel anterior cervical discectomy and fusion; ACCF, anterior cervical corpectomy and fusion; HDF, hybrid decompression and fusion; mACDF-CA, multilevel anterior cervical discectomy and fusion with cage alone 

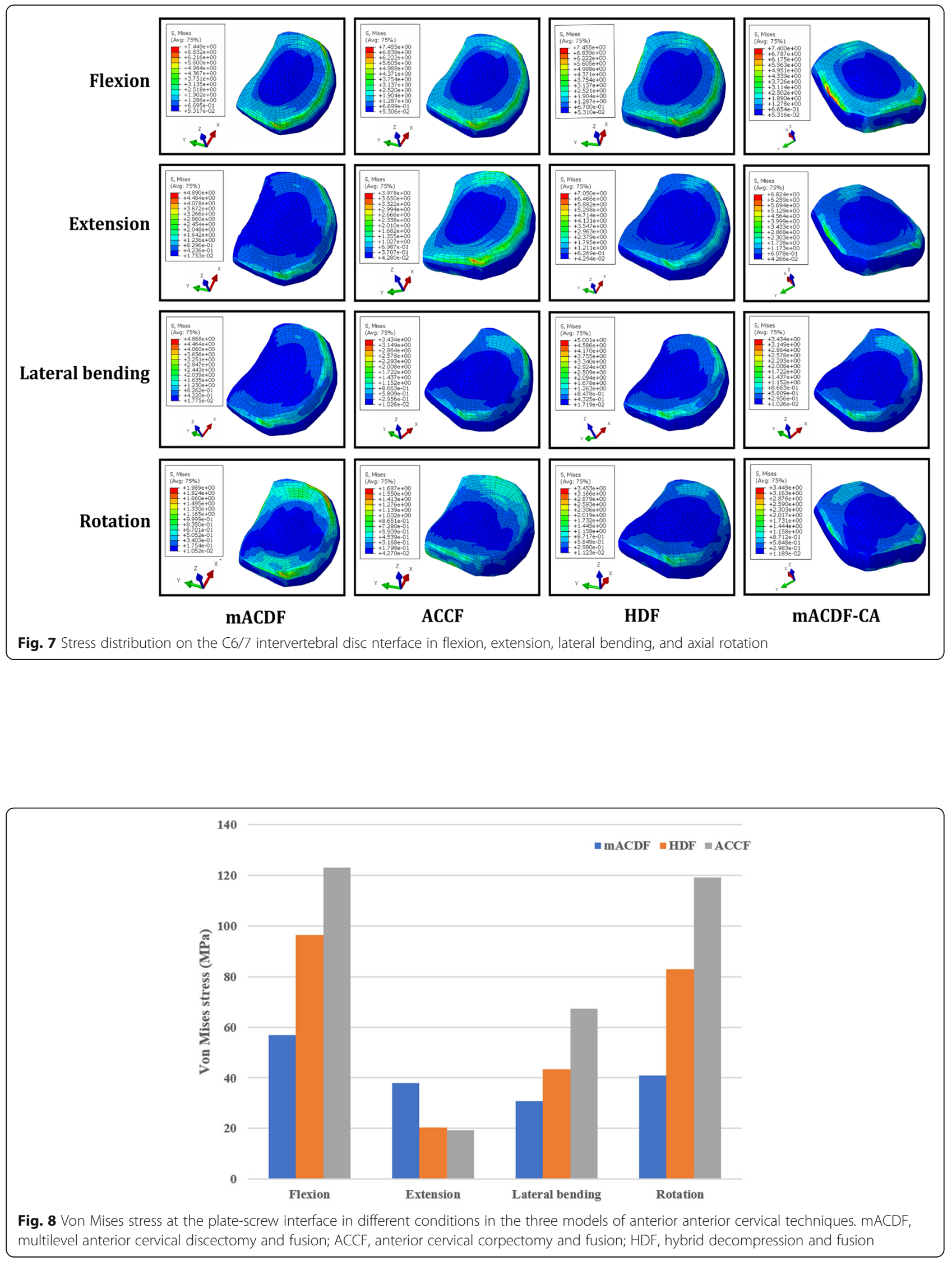


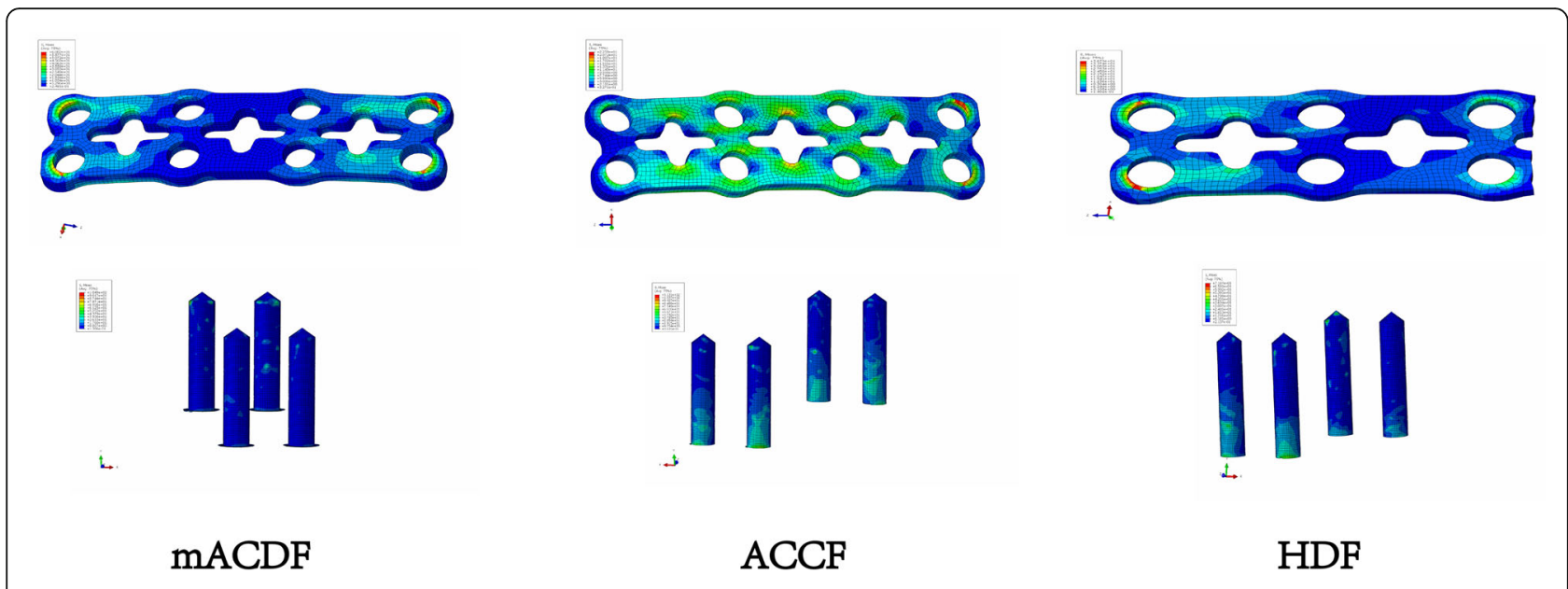

Fig. 9 Stress distribution on the plate-screw interface in the three models of anterior anterior cervical techniques in flexion

\section{Discussion}

2Cervical spondylosis is a common disease in middleaged and older people, for which surgery is a major treatment. Anterior cervical decompression and bone graft fusion is considered the standard surgical procedure for one- or two-level cervical spondylosis. However, for multilevel (three or more level) cervical spondylosis, controversy remains over the surgical approach [3-10]. As the etiological factors of MCSM usually arise from anterior degenerated intervertebral discs and osteophytes, it is challenging to remove the anterior compressive material through a simple posterior surgery, which cannot achieve effective decompression. Furthermore, posterior surgery cannot fully restore the physiological curvature of the cervical spine. Therefore, many researchers choose anterior surgery rather than posterior surgery [34]. More often than not, multiple levels are involved and complicate the surgical management. Anterior, posterior, and circumferential procedures have all been advocated. Even when the discussion is limited to anterior procedures, there is no agreement as to which reconstruction technique is best after multilevel anterior cervical decompression [1, 3, 4, 8, 9, 11, 16, 34-40].

Anterior surgical approaches mainly include ACCF, $\mathrm{ACDF}$, and HDF. Among the several anterior surgical approaches for MCSM, each has advantages and disadvantages $[1-4,8,9,11,16,34-45]$. In conventional ACDF surgery, osteophytes and degenerated intervertebral discs are removed from the posterior upper and lower margins of the vertebral body through an intervertebral space approach. This approach effectively removes the direct compression factors and provides good stability as well as multipoint expansion for better recovery and preservation of the physiological curvature of the cervical spine. Therefore, this approach is especially suitable for patients with straight or kyphotic curvature of the cervical spine $[11,35,46]$. However, this surgery involves a long operation time, has a limited field of view, and requires high surgical skills, making it difficult to ensure complete decompression in most cases [13-15].

ACCF involves long-segment decompression with slotting followed by long titanium mesh or autogenous bone grafting. The advantage of this approach is that it can be performed under direct vision, with a wider intraoperative view and larger operative field, and that it allows more extensive and thorough decompression [10, 37, 39, $41-43,47,48]$. The resected vertebral body can be used as a bone autograft, thus preventing the risk associated with bone allografts and complications, such as pain in the bone removal area. Moreover, the size of the grafthost bone interface requiring postoperative healing is reduced compared with that in ACDF, which is beneficial to improve the fusion rate after surgery. The disadvantage of ACCF is that it results in considerable damage to the structural stability of the anterior and middle columns $[1,4,8,16,35,49]$. Furthermore, iliac bone autografts collapse easily, and may become displaced or form a false joint. Long titanium mesh or fibular autografts are not conducive to restoring physiological lordosis of the cervical spine. In addition, owing to the multiple fixed segments and long moment arm, the monocortically-fixed screws at both ends of the titanium plate bear considerable stress, which may lead to postoperative complications, such as loosening and displacement. If the implanted bone is too long, surgical difficulty increases. Moreover, the fusion rate of longsegment bone grafting is substantially reduced, and the complication rate increases. ACCF surgery is mainly suitable for cases with lesions extending to the posterior vertebral body, extensive and severe osteophyte formation and vertebral body deformity in the anterior spinal cord, and contiguous stenosis of adjacent intervertebral spaces causing spinal cord compression. 
Another anterior surgical approach is HDF, namely ACCF combined with ACDF [3, 12]. Generally, the most severely compressed vertebral body is removed in HDF, and discectomy is performed only at the less compressed sites, which reduces the number of resected vertebral bodies. While achieving full decompression, this approach also reduces damage to the anterior vertebral column, which shortens the length of the bone graft, reduces the graft-host bone interface, and theoretically, lowers the probability of upper false joint formation. However, this approach is also associated with loss of cervical lordosis and bone graft-titanium plant-related complications.

Anterior titanium plating is required with conventional mACDF, ACCF, and HDF to treat MCSM. The application of an anterior locking titanium plate can effectively improve the stability and firmness of the fused cervical spine and greatly increase the fusion rate. In addition, using a plate prevents loss of intervertebral height, while the physiological curvature of the cervical spine is maintained, to some extent. However, with increasing plate length, stress at the plate-screw interface increases correspondingly, which increases the risk of implant loosening, displacement, and fracture. Moreover, following the application of a long-segment titanium plate, patients are prone to foreign body sensation, dysphagia, and even esophageal fistula, while the incidence of ASD is also increased [13-18]. In the present study, our biomechanical results showed that among the three surgical models involving titanium plate fixation (mACDF, ACCF, and HDF groups), the ACCF group had the highest stress at the plate-screw interface, the HDF group had higher stress than the mACDF group, and the mACDF group had the lowest stress. These results revealed that the risk of titanium plate or screw loosening, displacement, and fracture was the highest following ACCF, which is similar to clinical results. Furthermore, we found that stress in the intervertebral fusion cage also differed substantially between the mACDF and mACDF-CA groups. The mACDF-CA group showed markedly higher stress than the mACDF group, which may indicate a higher risk of fusion cage subsidence in the mACDF-CA group compared with the mACDF group. However, this speculation must be verified with long-term follow-up results from controlled clinical trials with large sample sizes.

To overcome the problems associated with anterior cervical titanium plating, a novel intervertebral fusion system that integrates support, fixation, and fusion; does not protrude from the anterior margin of the vertebral body; and effectively reduces surgical complications has been designed and applied clinically. This system can be independently applied in ACDF surgery without requiring anterior titanium plate fixation. The system highlights establishing cervical stability while minimizing interference with adjacent tissues by the implant, and considerably reduces the incidence and severity of associated complications after surgery. The system has achieved satisfactory results in its preliminary clinical applications [9, 19, 20, 50-54]. The currently available self-stabilizing zero-profile anterior cervical interbody fusion and internal fixation systems are the Zero-P system (Synthes, Switzerland) and the Fidji cage system (Zimmer, France). Strong evidence from basic research and clinical use have demonstrated the effectiveness of these systems [9, 19, 20, 50-55].

ASD has always been a potential long-term complication following anterior cervical fusion, and the incidence of ASD is even higher following long-segment fusion, which has attracted increasing attention. The incidence of ASD within 10 years after primary anterior cervical surgery is $25 \%$, and more than $15 \%$ of patients require secondary surgery owing to ASD [16-18, 56-59]. The mechanisms underpinning the development of ASD are still unclear, and the widely accepted mechanisms are local biomechanical changes in the cervical spine and natural degeneration of adjacent segments. Other risk factors are advanced age, multilevel fusion, postoperative cervical alignment change, an excessively long titanium plate, surgical injury to the adjacent intervertebral discs, and preoperative degeneration of adjacent segments. Controversy continues regarding whether differences exist in the impact of anterior cervical fusion on adjacent segments. Based on a 2-year follow-up of 218 patients undergoing single- or two-level ACCF, Park et al. [56] found that the incidence of ASD in the upper adjacent segment was markedly higher than that in the lower adjacent segment following ACCF (58\% vs. 28\%, respectively). In addition, Yang et al. [57] conducted a 5-year follow-up of 370 patients who underwent anterior cervical fusion without titanium plate implantation, and found that the incidence of ASD in the upper adjacent segment was considerably higher than that in the lower adjacent segment ( $5 \%$ vs. $1 \%$, respectively). However, in a 5.6-year follow-up study, Koller et al. [58] found no significant difference in the incidence of ASD between the upper and lower segments adjacent to the fused segment following anterior cervical fusion $(41.2 \%$ vs. $50.0 \%$, respectively). Similarly, Goffin et al. [59] followed 25 patients for an average of 7 years and found that $24 \%$ of the patients had ASD in the upper adjacent segment, while $28 \%$ had ASD in the lower adjacent segment; the difference between the two groups was not significant. In the present study, we found that with all four anterior cervical approaches, stress on the intervertebral discs at the adjacent segments was always higher for the upper disc compared with the lower disc under different conditions (flexion, extension, lateral bending, and rotation). 
This result suggests that after fusion, the upper adjacent segment was subjected to higher stress, which may accelerate dehydration and degeneration of the adjacent intervertebral disc, leading easily to ASD at this segment. A plausible reason for this difference is that the lower segment has greater mobility, which is conducive to stress load sharing; however, this hypothesis requires further clinical verification. Furthermore, we found that stress on the intervertebral discs at the adjacent segments was lowest in the mACDF-CA group and highest in the ACCF group. Biomechanically, this result revealed that mACDF-CA had the least impact on the adjacent segments compared with mACDF, HDF, and ACCF. However, whether mACDF-CA effectively prevents ASD remains to be clinically verified.

\section{Conclusions}

In summary, our biomechanical analysis indicated that among the four surgical approaches to anterior cervical fusion and internal fixation to treat MCSM, mACDF-CA had the least impact on the biomechanics of adjacent segments, and theoretically could reduce the incidence of ASD. However, this approach is associated with increased risk of fusion cage subsidence. In addition, stress at the titanium plate-screw interface was highest in the ACCF group and lowest in the mACDF group, which indicates the highest risk of titanium plate screw loosening, displacement, and fracture after ACCF. This study presented biomechanical evidence for the surgical treatment of MCSM and also provided strategies for preventing or reducing associated complications. However, further experiments and prospective clinical trials must be conducted to verify our findings.

\section{Abbreviations \\ ACDF: Anterior cervical discectomy and fusion; ALL: Anterior longitudinal ligament; ASD: Adjacent segment disease; CSM: Cervical spondylotic myelopathy; CT: Computed tomography; FE: Finite element; HDF: Hybrid decompression and fusion; mACDF: Multilevel anterior cervical discectomy and fusion; mACDF-CA: Multilevel anterior cervical discectomy and fusion with cage alone; MCSM: Multilevel cervical spondylotic myelopathy; PLL: Posterior longitudinal ligament; ROM: Range of motion}

\section{Acknowledgements}

We would like to thank the person who gave assistance to this study.

\section{Authors' contributions}

$\mathrm{ZHL}$ contributed to the design of the study. ZHL drafted the manuscript with the help from HL, MY and WTZ. HL and YM helped in the statistical analyses. Statistical analyses were discussed with MY and WTZ. ZHL and HL contributed to the revision. All authors have read and approved the final manuscript.

\section{Funding}

This study was supported by LiaoNing Revitalization Talents Program (XLYC1807131) and the Science and Technology Innovation Foundation of Dalian (2020JJ27SN070) for analysis and interpretation of data. The funders had no role in the study design, data collection and analysis, decision to publish, or preparation of the manuscript.

\section{Availability of data and materials}

Summarized data have been presented in this manuscript. The raw data for this study are located and protected at First Affiliated Hospital of Dalian Medical University. Sharing of the raw data is not suggested, because a secondary analysis is planned.

\section{Declarations}

Ethics approval and consent to participate

This study was approved by the medical ethics committee of First Affiliated Hospital of Dalian Medical University (PJ-KS-KY-2020-55), and informed written consent was obtained.

\section{Consent for publication}

Not applicable.

\section{Competing interests}

The authors declare that they have no competing interests.

\section{Author details}

'Department of Orthopaedics, First Affiliated Hospital of Dalian Medical University, Dalian, People's Republic of China. ${ }^{2}$ Key Laboratory of Molecular Mechanism for Repair and Remodeling of Orthopaedic Diseases, Liaoning Province, People's Republic of China. ${ }^{3}$ Seventh Medical Center of PLA General Hospital, Beijing, People's Republic of China.

Received: 26 December 2020 Accepted: 3 March 2021

Published online: 15 March 2021

\section{References}

1. Lin Q, Zhou X, Wang X, Cao P, Tsai N, Yuan W. A comparison of anterior cervical discectomy and corpectomy in patients with multilevel cervical spondylotic myelopathy. Eur Spine J. 2012;21(3):474-81. https://doi.org/10.1 007/s00586-011-1961-9.

2. Wei-bing X, Wun-Jer S, Gang L, Yue Z, Ming-xi J, Lian-shun J. Reconstructive techniques study after anterior decompression of multilevel cervical spondylotic myelopathy. J Spinal Disord Tech. 2009;22(7):511-5. https://doi. org/10.1097/BSD.0b013e3181a6a1fa.

3. Ryu WHA, Platt A, Deutsch H. Hybrid decompression and reconstruction technique for cervical spondylotic myelopathy: case series and review of the literature. J Spine Surg. 2020;6(1):181-95. https://doi.org/10.21037/jss.201 9.12.08.

4. Li Z, Huang J, Zhang Z, Li F, Hou T, Hou S. A comparison of multilevel anterior cervical discectomy and corpectomy in patients with 4-level cervical spondylotic myelopathy: a minimum 2-year follow-up study: multilevel anterior cervical discectomy. Clin Spine Surg. 2017;30(5):E540-6. https://doi.org/10.1097/BSD.0000000000000212.

5. Manzano GR, Casella G, Wang MY, Vanni S, Levi AD. A prospective, randomized trial comparing expansile cervical laminoplasty and cervical laminectomy and fusion for multilevel cervical myelopathy. Neurosurgery. 2012;70(2):264-77. https://doi.org/10.1227/NEU.0b013e3182305669.

6. Martin-Benlloch JA, Maruenda-Paulino Jl, Barra-Pla A, Laguia-Garzaran M. Expansive laminoplasty as a method for managing cervical multilevel spondylotic myelopathy. Spine (Phila Pa 1976). 2003;28(7):680-4. https://doi. org/10.1097/01.BRS.0000051913.55259.5F.

7. Huang RC, Girardi FP, Poynton AR, Cammisa FP Jr. Treatment of multilevel cervical spondylotic myeloradiculopathy with posterior decompression and fusion with lateral mass plate fixation and local bone graft. J Spinal Disord Tech. 2003;16(2):123-9. https://doi.org/10.1097/00024720-200304000-00002.

8. Li Z, Wang H, Tang J, Ren D, Li L, Hou S, Zhang H, Hou T. Comparison of three reconstructive techniques in the surgical management of patients with four-level cervical spondylotic myelopathy. Spine (Phila Pa 1976). 2017; 42(10):E575-83. https://doi.org/10.1097/BRS.0000000000001907.

9. Li Z, Zhao Y, Tang J, Ren D, Guo J, Wang H, Li L, Hou S. A comparison of a new zero-profile, stand-alone Fidji cervical cage and anterior cervical plate for single and multilevel ACDF: a minimum 2-year follow-up study. Eur Spine J. 2017;26(4):1129-39. https://doi.org/10.1007/s00586-016-4739-2.

10. Li Z, Guo Z, Hou S, Zhao Y, Zhong H, Yu S, Hou T. Segmental anterior cervical corpectomy and fusion with preservation of middle vertebrae in the surgical management of 4-level cervical spondylotic myelopathy. Eur Spine J. 2014;23(7):1472-9. https://doi.org/10.1007/s00586-014-3208-z. 
11. Yue WM, Brodner W, Highland TR. Long-term results after anterior cervical discectomy and fusion with allograft and plating: a 5- to 11-year radiologic and clinical follow-up study. Spine (Phila Pa 1976). 2005;30(19):2138-44. https://doi.org/10.1097/01.brs.0000180479.63092.17.

12. Zhou J, Li X, Zhou X, Lin H, Dong J. Anterior decompression and hybrid reconstruction with titanium mesh cage plus plate and self-locking standalone cage for the treatment of three-level cervical spondylotic myelopathy. J Clin Neurosci. 2017;43:196-201. https://doi.org/10.1016/j.jocn.2017.04.022.

13. Yee TJ, Swong K, Park P. Complications of anterior cervical spine surgery: a systematic review of the literature. J Spine Surg. 2020;6(1):302-22. https:// doi.org/10.21037/jss.2020.01.14.

14. Jung A, Schramm J. How to reduce recurrent laryngeal nerve palsy in anterior cervical spine surgery: a prospective observational study. Neurosurgery. 2010;67(1):10-5; discussion 15. https://doi.org/10.1227/01.NEU. 0000370203.26164 .24

15. Fountas KN, Kapsalaki EZ, Nikolakakos LG, Smisson HF, Johnston KW, Grigorian AA, Lee GP, Robinson JS Jr. Anterior cervical discectomy and fusion associated complications. Spine (Phila Pa 1976). 2007;32(21):2310-7. https://doi.org/10.1097/BRS.0b013e318154c57e.

16. Lau D, Chou D, Mummaneni PV. Two-level corpectomy versus three-level discectomy for cervical spondylotic myelopathy: a comparison of perioperative, radiographic, and clinical outcomes. J Neurosurg Spine. 2015; 23(3):280-9. https://doi.org/10.3171/2014.12.SPINE14545.

17. Chung JY, Park JB, Seo HY, Kim SK. Adjacent segment pathology after anterior cervical fusion. Asian Spine J. 2016;10(3):582-92. https://doi.org/1 0.4184/asj.2016.10.3.582.

18. Butler JS, Morrissey PB, Wagner SC, Kaye ID, Sebastian AS, Schroeder GD, Vaccaro AR, Hilibrand AS. Surgical strategies to prevent adjacent segment disease in the cervical spine. Clin Spine Surg. 2019;32(3):91-7. https://doi. org/10.1097/BSD.0000000000000632.

19. Huang SL, Yan HW, Wang KZ. Use of Fidji cervical cage in the treatment of cervical spinal cord injury without radiographic abnormality. Biomed Res Int. 2013;2013:810172.

20. Li Z, Wang H, Li L, Tang J, Ren D, Hou S. A new zero-profile, stand-alone Fidji cervical cage for the treatment of the single and multilevel cervical degenerative disc disease. J Clin Neurosci. 2017;41:115-22. https://doi.org/1 0.1016/j.jocn.2017.02.043

21. Brolin K, Halldin P. Development of a finite element model of the upper cervical spine and a parameter study of ligament characteristics. Spine (Phila Pa 1976). 2004;29(4):376-85. https://doi.org/10.1097/01.BRS.000009082 0.99182.2D.

22. Dong L, Li G, Mao H, Marek S, Yang KH. Development and validation of a 10-year-old child ligamentous cervical spine finite element model. Ann Biomed Eng. 2013;41(12):2538-52. https://doi.org/10.1007/s10439013-0858-7.

23. Faizan A, Goel VK, Garfin SR, Bono CM, Serhan H, Biyani A, Elgafy H, Krishna $M$, Friesem T. Do design variations in the artificial disc influence cervical spine biomechanics? A finite element investigation. Eur Spine J. 2012; 21(Suppl 5):S653-62.

24. $L i X F$, Jin $L Y$, Liang $C G$, Yin $H L$, Song $X X$. Adjacent-level biomechanics after single-level anterior cervical interbody fusion with anchored zero-profile spacer versus cage-plate construct: a finite element study. BMC Surg. 2020; 20(1):66. https://doi.org/10.1186/s12893-020-00729-4.

25. Yoganandan N, Kumaresan S, Pintar FA. Geometric and mechanical properties of human cervical spine ligaments. J Biomech Eng. 2000;122(6): 623-9. https://doi.org/10.1115/1.1322034.

26. Yoganandan N, Kumaresan S, Pintar FA. Biomechanics of the cervical spine part 2. Cervical spine soft tissue responses and biomechanical modeling. Clin Biomech. 2001;16(1):1-27. https://doi.org/10.1016/S02680033(00)00074-7.

27. Lee SH, Im YJ, Kim KT, Kim YH, Park WM, Kim K. Comparison of cervical spine biomechanics after fixed- and mobile-core artificial disc replacement: a finite element analysis. Spine (Phila Pa 1976). 2011;36(9):700-8. https://doi. org/10.1097/BRS.0b013e3181f5cb87.

28. Hussain M, Natarajan RN, Fayyazi AH, Braaksma BR, Andersson GB, An HS. Screw angulation affects bone-screw stresses and bone graft load sharing in anterior cervical corpectomy fusion with a rigid screw-plate construct: a finite element model study. Spine J. 2009;9(12):1016-23. https://doi.org/10.1 016/j.spinee.2009.08.461.

29. Wang Z, Zhao H, Liu JM, Chao R, Chen TB, Tan LW, Zhu F, Zhao JH, Liu P. Biomechanics of anterior plating failure in treating distractive flexion injury in the caudal subaxial cervical spine. Clin Biomech. 2017;50:130-8. https:// doi.org/10.1016/j.clinbiomech.2017.10.017.

30. Wu TK, Meng Y, Wang BY, Rong X, Hong Y, Ding C, Chen H, Liu H. Biomechanics following skip-level cervical disc arthroplasty versus skip-level cervical discectomy and fusion: a finite element-based study. BMC Musculoskelet Disord. 2019;20(1):49. https://doi.org/10.1186/s12891-019-2425-3.

31. Lee JH, Park WM, Kim YH, Jahng TA. A biomechanical analysis of an artificial disc with a shock-absorbing core property by using whole-cervical spine finite element analysis. Spine (Phila Pa 1976). 2016;41(15):E893-901. https:// doi.org/10.1097/BRS.0000000000001468.

32. Panjabi MM, Crisco JJ, Vasavada A, Oda T, Cholewicki J, Nibu K, Shin E. Mechanical properties of the human cervical spine as shown by threedimensional load-displacement curves. Spine (Phila Pa 1976). 2001;26(24): 2692-700. https://doi.org/10.1097/00007632-200112150-00012.

33. Liu Q, Guo Q, Yang J, Zhang P, Xu T, Cheng X, Chen J, Guan H, Ni B. Subaxial cervical intradiscal pressure and segmental kinematics following atlantoaxial fixation in different angles. World Neurosurg. 2016;87:521-8. https://doi.org/10.1016/j.wneu.2015.09.025.

34. Huang JJ, Niu CC, Chen LH, Lai PL, Fu TS, Chen WJ. Anterior cervical spinal surgery for multilevel cervical myelopathy. Chang Gung Med J. 2004;27(7): 531-41.

35. Shamji MF, Massicotte EM, Traynelis VC, Norvell DC, Hermsmeyer JT, Fehlings MG. Comparison of anterior surgical options for the treatment of multilevel cervical spondylotic myelopathy: a systematic review. Spine (Phila Pa 1976). 2013;38(22 Suppl 1):S195-209. https://doi.org/10.1097/BRS.0b013 e3182a7eb27.

36. Liu Y, Hou Y, Yang L, Chen H, Wang X, Wu X, Gao R, Wang C, Yuan W. Comparison of 3 reconstructive techniques in the surgical management of multilevel cervical spondylotic myelopathy. Spine (Phila Pa 1976). 2012; 37(23):E1450-8. https://doi.org/10.1097/BRS.0b013e31826c72b4.

37. Dalbayrak S, Yilmaz M, Naderi S. "Skip" corpectomy in the treatment of multilevel cervical spondylotic myelopathy and ossified posterior longitudinal ligament. J Neurosurg Spine. 2010;12(1):33-8. https://doi.org/1 0.3171/2009.7.SPINE08965.

38. Chibbaro S, Mirone G, Makiese O, George B. Multilevel oblique corpectomy without fusion in managing cervical myelopathy: long-term outcome and stability evaluation in 268 patients. J Neurosurg Spine. 2009;10(5):458-65. https://doi.org/10.3171/2009.1.SPINE08186.

39. Ikenaga M, Shikata J, Tanaka C. Anterior corpectomy and fusion with fibular strut grafts for multilevel cervical myelopathy. J Neurosurg Spine. 2005;3(2): 79-85. https://doi.org/10.3171/spi.2005.3.2.0079.

40. Ashkenazi E, Smorgick Y, Rand N, Millgram MA, Mirovsky Y, Floman Y. Anterior decompression combined with corpectomies and discectomies in the management of multilevel cervical myelopathy: a hybrid decompression and fixation technique. J Neurosurg Spine. 2005;3(3):205-9. https://doi.org/10.3171/spi.2005.3.3.0205.

41. Ikenaga M, Shikata J, Tanaka C. Long-term results over 10 years of anterior corpectomy and fusion for multilevel cervical myelopathy. Spine (Phila Pa 1976). 2006;31(14):1568-74; discussion 1575. https://doi.org/10.1097/01.brs. 0000221985.37468.0f.

42. Hackel M, Stejskal L, Kramar F. Anterior cervical corpectomy in the treatment of multilevel degenerative stenoses with spondylotic myelopathy. Personal experience with therapy and a literature review. Rozhl Chir. 2001; 80(4):163-9.

43. Macdonald RL, Fehlings MG, Tator CH, Lozano A, Fleming JR, Gentili F, Bernstein M, Wallace MC, Tasker RR. Multilevel anterior cervical corpectomy and fibular allograft fusion for cervical myelopathy. J Neurosurg. 1997;86(6): 990-7. https://doi.org/10.3171/jns.1997.86.6.0990.

44. Yang KQ, Lu XS, Cai QL, Ye LX, Lu WQ. Anterior multilevel decompression and fusion for cervical spondylotic myelopathy. Report of 214 cases. Chin Med J. 1985;98(1):1-6.

45. Mann KS, Khosla VK, Gulati DR. Cervical spondylotic myelopathy treated by single-stage multilevel anterior decompression. A prospective study. J Neurosurg. 1984;60(1):81-7. https://doi.org/10.3171/jns.1984.60.1.0081.

46. Hillard VH, Apfelbaum RI. Surgical management of cervical myelopathy: indications and techniques for multilevel cervical discectomy. Spine J. 2006; 6(6 Suppl):242S-51S. https://doi.org/10.1016/j.spinee.2006.05.005.

47. Chacko AG, Joseph M, Turel MK, Prabhu K, Daniel RT, Jacob KS. Multilevel oblique corpectomy for cervical spondylotic myelopathy preserves segmental motion. Eur Spine J. 2012;21(7):1360-7. https://doi.org/10.1007/ s00586-011-2137-3. 
48. George B, Gauthier N, Lot G. Multisegmental cervical spondylotic myelopathy and radiculopathy treated by multilevel oblique corpectomies without fusion. Neurosurgery. 1999;44(1):81-90. https://doi.org/10.1097/ 00006123-199901000-00046.

49. Liu Y, Qi M, Chen H, Yang L, Wang X, Shi G, Gao R, Wang C, Yuan W. Comparative analysis of complications of different reconstructive techniques following anterior decompression for multilevel cervical spondylotic myelopathy. Eur Spine J. 2012;21(12):2428-35. https://doi.org/10.1007/ s00586-012-2323-y

50. Wang Z, Jiang W, Li X, Wang H, Shi J, Chen J, Meng B, Yang H. The application of zero-profile anchored spacer in anterior cervical discectomy and fusion. Eur Spine J. 2015;24(1):148-54. https://doi.org/10.1007/s00586014-3628-9.

51. Shao H, Chen J, Ru B, Yan F, Zhang J, Xu S, Huang Y. Zero-profile implant versus conventional cage-plate implant in anterior cervical discectomy and fusion for the treatment of degenerative cervical spondylosis: a metaanalysis. J Orthop Surg Res. 2015;10(1):148. https://doi.org/10.1186/s13018015-0290-9.

52. Hofstetter CP, Kesavabhotla K, Boockvar JA. Zero-profile anchored spacer reduces rate of dysphagia compared with ACDF with anterior plating. J Spinal Disord Tech. 2015;28(5):E284-90. https://doi.org/10.1097/BSD.0b013 e31828873ed.

53. Miao J, Shen Y, Kuang Y, Yang L, Wang X, Chen Y, Chen D. Early follow-up outcomes of a new zero-profile implant used in anterior cervical discectomy and fusion. J Spinal Disord Tech. 2013;26(5):E193-7. https://doi. org/10.1097/BSD.0b013e31827a2812.

54. Barbagallo GM, Romano D, Certo F, Milone P, Albanese V. Zero-P: a new zero-profile cage-plate device for single and multilevel ACDF. A single institution series with four years maximum follow-up and review of the literature on zero-profile devices. Eur Spine J. 2013;22(Suppl 6):S868-78.

55. Scholz M, Reyes PM, Schleicher P, Sawa AG, Baek S, Kandziora F, Marciano FF, Crawford NR. A new stand-alone cervical anterior interbody fusion device: biomechanical comparison with established anterior cervical fixation devices. Spine (Phila Pa 1976). 2009;34(2):156-60. https://doi.org/10.1097/ BRS.0b013e31818ff9c4.

56. Park DH, Ramakrishnan P, Cho TH, Lorenz E, Eck JC, Humphreys SC, Lim TH. Effect of lower two-level anterior cervical fusion on the superior adjacent level. J Neurosurg Spine. 2007;7(3):336-40. https://doi.org/10.3171/SPI-07/ 09/336.

57. Yang JY, Song HS, Lee M, Bohlman HH, Riew KD. Adjacent level ossification development after anterior cervical fusion without plate fixation. Spine (Phila Pa 1976). 2009;34(1):30-3. https://doi.org/10.1097/BRS.0b013e3181 90d833.

58. Koller H, Reynolds J, Zenner J, Forstner R, Hempfing A, Maislinger I, Kolb K, Tauber M, Resch H, Mayer M, Hitzl W. Mid- to long-term outcome of instrumented anterior cervical fusion for subaxial injuries. Eur Spine J. 2009; 18(5):630-53. https://doi.org/10.1007/s00586-008-0879-3.

59. Goffin J, van Loon J, Van Calenbergh F, Plets C. Long-term results after anterior cervical fusion and osteosynthetic stabilization for fractures and/or dislocations of the cervical spine. J Spinal Disord. 1995;8(6):5008 discussion 499.

\section{Publisher's Note}

Springer Nature remains neutral with regard to jurisdictional claims in published maps and institutional affiliations.

\section{Ready to submit your research? Choose BMC and benefit from}

- fast, convenient online submission

- thorough peer review by experienced researchers in your field

- rapid publication on acceptance

- support for research data, including large and complex data types

- gold Open Access which fosters wider collaboration and increased citations

- maximum visibility for your research: over $100 \mathrm{M}$ website views per year

At BMC, research is always in progress.

Learn more biomedcentral.com/submissions 